\title{
Kajian Rumah Sehat di Kampung Kumuh Kelurahan Morokrembangan Surabaya
}

\author{
Kusumastuti, Widjonarko, Endang Sri Sukaptini, Srie Subekti \\ Program Studi Diploma Teknik Sipil FTSP ITS, Surabaya \\ Email: kusumastuti.its@hotmail.com,widjonarko.roestam@its.ac.id,niniek@ce.its.ac.id
}

\begin{abstract}
Morokrembangan kampong is one of the settlements which has poor environmental conditions. Sanitary houses in the kampong Morokrembangan doesn't meet the standards. Poor environmental conditions resulted in a number of settlements affected by the tuberculosis disease (TB). That were caused by unhealthy housing and slums condition, the average of building area is $24 \mathrm{~m}^{2}$ which is occupied by eight people and wasn't equipped with a kitchen chimney, window, light and air ventilation. Ideally, ventilation width is $10 \%$ to $20 \%$ of the floor area. It makes well air circulation in the house. Fresh air easily enters the room to replace dirty air. This research aim to determine the condition of the house in terms of the density of occupants in the house, ventilation, humidity, clean water facility, has SPAL (wastewater disposal), and trash. Data obtained through questionnaires, interviews, and physical observation of the houses in Morokrembangan kampong. Results of this study indicated that $26,44 \%$ of the houses is in unhealthy category, 86.700 houses has not meet the healty requirements of the 327.915 houses surveyed.
\end{abstract}

Keywords: density of occupants, ventilation, clean water, and SPAL.

Abstrak

Kampung Morokrembangan merupakan salah satu permukiman yang kondisi lingkungannya kurang memenuhi syarat kesehatan. Sanitasi rumah-rumah di kampung Morokrembangan tidak memenuhi standar. Buruknya kondisi lingkungan permukimannya mengakibatkan sejumlah warga terkena penyakit tuberkulosis $(T B)$. Hal ini diakibatkan oleh kondisi rumah tak sehat dan kumuh, rata-rata luas bangunan $24 \mathbf{m}^{2}$ dihuni delapan orang dan tidak dilengkapi dengan lubang asap dapur, ventilasi udara, cahaya, dan jendela, karena idealnya luas ventilasi terdiri atas $10 \%$. $20 \%$ dari luas lantai bangunan. Adanya ventilasi ini membantu udara keluar masuk dengan baik. Udara segar masuk ke dalam ruang menggantikan udara kotor di dalam ruangan. Tujuan penelitian ini untuk mengetahui kondisi rumah ditinjau dari kepadatan penghuni dalam satu rumah, ventilasi, pencahayaan, kelembaban, sarana air bersih, mempunyai SPAL (sarana pembuangan air limbah), dan tempat sampah. Data primer diperoleh dengan wawancara, kuisioner, dan pengamatan kondisi fisik rumah di kampung Morokrembangan. Hasil penelitian ini menunjukkan bahwa terdapat $26,44 \%$ rumah tak sehat, yaitu terdapat 86.700 rumah tak memenuhi persyaratan rumah sehat dari 327.915 rumah yang disurvei.

Kata Kunci: kepadatan penghuni, ventilasi, air bersih, dan SPAL.

\section{Pendahuluan}

Kelurahan Morokrembangan termasuk wilayah Kecamatan Krembangan dengan batas-batas sisi barat, Kelurahan Kalianak; utara, Laut Jawa; timur, Kelurahan Perak Barat; dan selatan, Kelurahan Dupak dan Buzem. Dimana batas selatan merupakan kawasan yang diatasnya melintas jalan tol Waru-Perak.
Selain permukiman terdapat kawasan pendidikan TNI-AL (kodikal dan komando pendidikan laut).

Rumah sehat ikut menentukan kesehatan sebuah keluarga. Sebab, jika jauh dari standar, berbagai penyakit akan mengancam. Karena itu, sebelum membangun rumah, maka ventilasi dan

Jurnal APLIKASI: Media Informasi \& Komunikasi Aplikasi Teknik Sipil Terkini Halaman 25 
keperluan syarat rumah sehat lainnya harus diperhatikan, karena banyak penyakit yang bisa muncul bila orang tinggal di rumah yang tidak sehat. Karena rumah yang minim ventilasi, kuman penyakitnya tidak bisa keluar dan berkutat saja di dalam rumah tersebut. Jadi apabila penghuninya bisa sembuh, maka akan mudah tertular lagi untuk penyakit yang sama. Orang yang tinggal di rumah yang tidak sehat lebih beresiko mengalami penyakit tuberkulosis $(T B)$ dari pada orang yang tinggal di rumah sehat. Parahnya, penyakit tuberkulosis $(T B)$ mudah menular, apabila ada satu anggota keluarga yang menderita karena kuman mycobacterium tuberculosis tersebut, sangat mungkin anggota keluarga lainnya terkena penyakit yang sama. Penyakit lain yang juga beresiko muncul karena tinggal di rumah yang kurang sehat adalah penyakit kulit, hal ini karena terkait dengan jamur. Penyakit kulit terutama menyerang orang yang tinggal di rumah dengan tingkat kelembaban tinggi. Kondisi lembab pada lantai maupun dinding rumah memudahkan tumbuhnya jamur, selain itu juga bisa mengalami alergi. Penyakit lain yang bisa muncul karena rumah tidak sehat adalah diare, hal ini disebabkan sanitasi yang buruk, sehingga membuat binatang, seperti nyamuk, lalat, kecoak, dan tikus masuk kedalam rumah. Padahal, binatang-binatang tersebut berpotensi membawa bibit penyakit yang membahayakan kesehatan penghuni rumah. Nyamuk merupakan faktor penyebab penyakit demam berdarah. Lalat sering terbang di makanan yang tidak ditutup.
Padahal lalat membawa bibit penyakit setelah hinggap di sampah maupun bahan tercemar lainnya.

Penelitian ini bertujuan untuk mengetahui kondisi rumah ditinjau dari kepadatan penghuni dalam satu rumah serta mengetahui kondisi rumah ditinjau dari ventilasi, pencahayaan, kelembaban, sarana air bersih, mempunyai SPAL (sarana pembuangan air limbah), dan tempat sampah.

\section{Metodologi}

Agenda 21 dan konsep sustainable development dalam pembangunan permukiman, yaitu permukiman yang aman, sehat, menyatu dengan lingkungannya, dan mendukung integrasi sosial. Dinas Kesehatan Kota Surabaya dalam Syarat Rumah Sehat dan Dampak Rumah Tak Sehat bagi Kesehatan. Penelitian ini merupakan kajian kepustakaan berupa review literatur yang mendukung data primer.

Teknik pengumpulan data diperoleh dari Pengumpulan data primer (wawancara, kuesioner, observasi) dan pengumpulan data sekunder dengan melakukan studi pustaka.

Tujuan dari analisis dan pembahasan adalah mengolah semua data yang terkumpul untuk mengetahui kaitan antara satu data dengan data lainnya. Penelitian ini dilakukan secara kuantitatif, yaitu penelitian yang sangat dipengaruhi oleh permasalahan yang ada maupun tujuan penelitian.

\section{Hasil dan Pembahasan}


Untuk memiliki rumah yang sehat, harus mengetahui syarat rumah sehat dan dampak rumah tak sehat seperti ditunjukkan pada tabel 1 dan 2 .

Tabel 1. Syarat Rumah Sehat

\begin{tabular}{cl}
\hline No. & \multicolumn{1}{c}{ Syarat Rumah Sehat } \\
\hline 1 & Total jendela $10 \%$ dari luas lantai \\
\hline & $\begin{array}{l}\text { Kepadatan penghuni, satu orang } \\
\text { dengan wilayah } 8 \mathrm{~m}^{2} \text { Misalnya, satu } \\
\text { rumah dengan luas lantai } 20 \mathrm{~m}^{2} . \text { Maka } \\
\text { maksimal terdapat tiga orang yang } \\
\text { tinggal dirumah tersebut }\end{array}$ \\
\hline 3 & $\begin{array}{l}\text { Kandang hewan peliharaan terpisah } \\
\text { dengan rumah penghuni. }\end{array}$ \\
\hline 4 & Konstruksi rumah permanen \\
\hline 5 & $\begin{array}{l}\text { Rumah memiliki sarana air bersih } \\
\text { (PDAM atau sumur) }\end{array}$ \\
\hline 6 & Terdapat jamban dan septictank. \\
\hline 7 & $\begin{array}{l}\text { Rumah mempunyai SPAL (sarana } \\
\text { pembuangan air limbah). }\end{array}$ \\
\hline 8 & $\begin{array}{l}\text { Terdapat tempat sampah di dalam dan } \\
\text { di luar rumah. }\end{array}$ \\
\hline 9 & $\begin{array}{l}\text { Adanya pekarangan dan kamar mandi } \\
\text { bebas jentik menjadi nilai lebih. }\end{array}$ \\
\hline
\end{tabular}

Sumber: Dinas Kesehatan Kota Surabaya tahun 2012

Dari hasil pengolahan data sebanyak 327.915 rumah yang disurvei di kampung Kelurahan Morokrembangan, terdapat 86.700 rumah atau 26,44\% yang tidak memenuhi persyaratan rumah sehat.

\subsection{Kondisi rumah ditinjau dari kepadatan penghuni dalam satu rumah}

Dari hasil pengolahan data terdapat 86.700 rumah yang tidak memenuhi persyaratan rumah sehat, dimana ratarata kepadatan penghuni dalam satu rumah terlalu padat, yaitu dengan luas bangunan keseluruhan $24 \mathrm{~m}^{2}$, dihuni 8 orang, terdiri dari suami, isteri, tiga orang anak, satu menantu, dan dua cucu; jadi rata-rata tiap orang $3 \mathrm{~m}^{2}$, sehingga terkesan kumuh. Di lantai satu rumah tersebut terdapat empat petak yang terdiri dari satu ruang tamu, satu kamar tanpa ventilasi, dapur, dan kamar mandi (Dinas Kesehatan Kota Surabaya, 2012).

Diantara semua ruang tersebut hanya ruang tamu dan dapur yang mempunyai jendela, sehingga lantai 1 rumah tersebut terkesan pengap, sedangkan untuk menghirup udara segar hanya di teras lantai 2 (balkon). Jadi faktor yang menyebabkan kekumuhan karena meningkatnya kepadatan hunian dan menurunnya kondisi lingkungan, karena kepadatan hunian rata-rata 3-6 $\mathrm{m}^{2}$ per orang, sedangkan menurut persyaratan dari Dinas Kesehatan Kota Surabaya minimal per orang $8 \mathrm{~m}^{2}$, dan menurut standar internasional per orang $10 \mathrm{~m}^{2}$ (Dinas Kesehatan Kota Surabaya, 2012).

\subsection{Kondisi rumah ditinjau dari ventilasi, pencahayaan, kelem- baban, sarana air bersih, mempunyai SPAL (sarana pem- buangan air limbah), dan tempat sampah}

Dari hasil pengolahan data terdapat 86.700 rumah yang tidak memenuhi persyaratan rumah sehat, dimana ratarata kondisi ventilasi rumahnya sangat buruk, banyak rumah yang kamar tidurnya tidak mempunyai ventilasi maupun penerangan cahaya, sehingga menjadi gelap dan pengap (Dinas Kesehatan 
Kota Surabaya, 2012).

Ventilasi udara dan ventilasi cahaya rata-rata hanya ada di ruang tamu, sedangkan untuk dapur meskipun ada tetapi ukuran ventilasinya kecil, hanya (50x50) $\mathrm{cm}$, padahal seharusnya setiap kamar harus mempunyai ventilasi diatas pintu dan jendela. Hal ini dimaksudkan untuk sirkulasi dan pertukaran udara. Menurut standar rumah sehat ventilasi/jendela tersebut minimal $10 \%$ $20 \%$ luas lantai, sebab adanya ventilasi /jendela untuk membantu udara keluar masuk dengan baik. Udara segar masuk kedalam ruang menggantikan udara kotor yang ada dalam ruang.

Rumah sebaiknya menggunakan plafon dan jangan menggunakan bahan asbes. Sebab, asbes mengeluarkan partikel kecil-kecil yang bisa terhirup, sehingga dapat membahayakan kesehatan, salah satunya dapat menyebabkan penyakit kanker paru-paru (Dinas Kesehatan Kota Surabaya, 2012).

Permasalahan yang paling krusial di kelurahan Morokrembangan adalah sangat minimnya jamban (MCK), karena banyak rumah pada permukiman tersebut yang penghuninya lebih dari satu keluarga, artinya dalam satu rumah dihuni oleh 2-3 keluarga (gambar 1).

Hal ini disebabkan banyaknya pendatang musiman yang tinggal di kelurahan tersebut. Disamping itu, banyak kos-kosan tanpa fasilitas toilet. Penghuni rumah masih membuang air kecil dan besar sembarangan. Dari data pada tahun 2009, satu kelurahan hanya mempunyai sekitar lima MCK (mandi, cuci, kakus), dan rata-rata satu MCK tidak mempunyai septictank.

Tabel 2. Dampak Rumah Tak Sehat bagi Kesehatan

\begin{tabular}{|c|c|}
\hline Tinjauan & Dampaknya bagi Kesehatan \\
\hline Pencahayaan & $\begin{array}{l}\text { Nilai pencahayaan yang } \\
\text { rendah akan mengakibatkan } \\
\text { kerusakan retina pada mata, } \\
\text { sedangkan yang terlalu tinggi } \\
\text { bisa mengakibatkan kenaikan } \\
\text { suhu pada ruang. }\end{array}$ \\
\hline Suhu & $\begin{array}{l}\text { Suhu yang terlalu rendah } \\
\text { dapat mengakibatkan gang- } \\
\text { guan kesehatan hingga hipo- } \\
\text { termia. Suhu yang terlalu } \\
\text { tinggi dapat mengakibatkan } \\
\text { dehidrasi sampai heat stroke. }\end{array}$ \\
\hline Debu & $\begin{array}{l}\text { Dapat mengakibatkan pneu- } \\
\text { monia, gangguan sistem per- } \\
\text { napasan, iritasi mata, alergi, } \\
\text { dan bronkitis kronis, PM 2,5 } \\
\text { dapat masuk ke dalam paru } \\
\text { yang mengakibatkan timbul- } \\
\text { nya emfisema paru, asma } \\
\text { bronchial, kanker paru-paru, } \\
\text { serta gangguan kardiovasku- } \\
\text { ler. }\end{array}$ \\
\hline Ventilasi & $\begin{array}{l}\text { Pertukaran udara yang tidak } \\
\text { memenuhi syarat dapat me- } \\
\text { ngakibatkan suburnya per- } \\
\text { tumbuhan mikro organisme } \\
\text { yang bisa mengganggu kese- } \\
\text { hatan manusia. }\end{array}$ \\
\hline Kelembaban & $\begin{array}{l}\text { Kelembaban yang terlalu } \\
\text { tinggi maupun rendah dapat } \\
\text { mengakibatkan suburnya per- } \\
\text { tumbuhan mikro organisme }\end{array}$ \\
\hline $\begin{array}{c}\text { Jamur dan } \\
\text { kuman }\end{array}$ & $\begin{array}{l}\text { Mengakibatkan penyakit in- } \\
\text { feksi seperti flu, hipersensi- } \\
\text { vitas (asma dan alergi), serta } \\
\text { toxicosis, yaitu toksin dalam } \\
\text { udara diruang yang terkon- } \\
\text { taminasi sebagai penyebab } \\
\text { gejala sick building syndro- } \\
\text { me (SBS). }\end{array}$ \\
\hline
\end{tabular}

Sumber: Dinas Kesehatan Kota Surabaya Tahun 2012

Saat ini (2013), satu kelurahan sudah mempunyai delapan MCK yang tersebar di sembilan RW, dan semua MCK mempunyai septictank. Untuk menjaga kebersihan MCK, ada warga yang 
ditunjuk untuk mengelolanya, dengan imbalan setiap warga yang ingin menggunakan MCK dikenai biaya Rp.500,-.

Kondisi rumah di kelurahan Morokrembangan rata-rata juga tidak mempunyai SPAL (sarana pembuangan air limbah), yaitu rumah-rumah tersebut tidak mempunyai saluran resmi untuk pembuangan air, dimana bak air dari kamar mandi ataupun tempat cuci piring, airnya dibiarkan tergenang sampai kering, dan hal ini merupakan sarang kuman yang menimbulkan penyakit.

Dari hasil pengolahan data terdapat 86.700 rumah yang tidak memenuhi persyaratan rumah sehat, dimana rata-rata rumahnya tidak memiliki sarana air bersih (PDAM atau sumur). Untuk keperluan memasak, warga membeli air bersih memakai jerigen-jerigen yang dibawa dengan gledekan.

Dari hasil pengolahan data terdapat 86.700 rumah yang tidak memenuhi persyaratan rumah sehat, dimana rata-rata rumahnya tidak memiliki tempat pembuangan sampah, baik di dalam maupun di luar rumah. Kondisi saat ini, satu kelurahan hanya mempunyai sembilan tempat pembuangan sampah, yang tersebar di sembilan RW.

\section{Simpulan}

Dari hasil pembahasan, dapat disimpulkan bahwa ada 86.700 rumah yang tidak memenuhi persyaratan rumah sehat, karena:

1. Kepadatan hunian rata-rata 3-6 $\mathrm{m}^{2}$ per orang, sedangkan menurut persyaratan dari Dinas Kesehatan Kota Surabaya minimal per orang $8 \mathrm{~m}^{2}$, dan menurut standar internasional per orang $10 \mathrm{~m}^{2}$.

2. Dalam satu kelurahan hanya mempunyai delapan MCK yang tersebar di sembilan RW, yang dilengkapi septictank. Kondisi rumahnya, ratarata juga tidak mempunyai SPAL (sarana pembuangan air limbah) yaitu rumah-rumah tersebut tidak mempunyai saluran resmi untuk pembuangan air, bak air dari kamar mandi ataupun tempat cuci piring, airnya dibiarkan tergenang sampai kering.

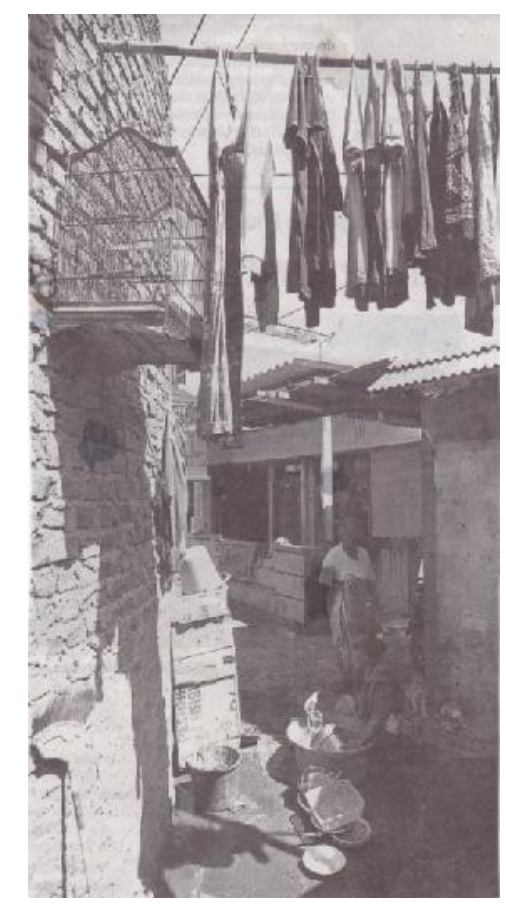

Gambar 1. Kondisi rumah di Kampung Morokrembangan yang rata-rata sanitasinya buruk.

3. Rata-rata setiap rumah tidak memiliki sarana air bersih (PDAM atau sumur). Untuk keperluan memasak, warga membeli air bersih memakai jerigenjerigen yang dibawa dengan gledekan.

4. Rata-rata setiap rumah tidak memiliki tempat pembuangan sampah, baik di 
dalam maupun di luar rumah. Kondisi saat ini, satu kelurahan hanya mempunyai sembilan tempat pembuangan sampah yang tersebar di sembilan RW.

\section{Daftar Pustaka}

Agenda 21 dan Konsep Sustainable Development dalam Pembangunan Permukiman.

Dinas Kesehatan Kota Surabaya. 2012. Syarat Rumah Sehat.

Silas, Johan. 1993. Housing Beyond Home. Case study of SurabayaITS.

Silas, Johan. 1996. Kampung Surabaya menuju Metropolitan. Surabaya: Yayasan Keluarga Bhakti.

Turner, John F.C., 1976. Housing By People, Tavards Autonomy in Building Environments. Morion Boyars Publisher Ltd., London: Great Britain.

Yudohusodo, Siswono. 1991. Rumah untuk seluruh Rakyat. INKOPPOL. unit Bharakerta Jakarta. 